\title{
Discrepâncias na descrição de materiais utilizados na confecção de órteses de membros superiores - mão e punho
}

\author{
Discrepancies in the description of materials used in the manufacture of upper limb \\ orthoses - wrist-hand segment
}

\author{
BARBOSA, Maria Lílian de Araújo; Mestranda; Universidade Federal do Paraná \\ liliandesigner@gmail.com \\ OKIMOTO, Maria Lucia Leite Ribeiro; Dra.; Universidade Federal do Paraná \\ lucia.demec@ufpr.br \\ RIBEIRO, Gisele Yumi Arabori; Mestranda; Universidade Federal do Paraná \\ gisele.yr@gmail.com \\ MERINO, Eugenio Andrés Díaz; Dr.; Universidade Federal de Santa Catarina \\ eugenio.merino@ufsc.br \\ MERINO, Gisele Schimidt A. Diaz; Dra.; Universidade Federal de Santa Catarina \\ gisellemerino@gmail.com \\ CATAPAN, Marcio Fontana; Dr.; Universidade Federal do Paraná \\ marciocatapan@gmail.com
}

\section{Resumo}

Uma das causas de afastamentos do trabalho, são acidentes com as mãos, representando $18 \%$ de todos os acidentes relatados. A órtese é um dispositivo de tecnologia assistiva, usada para reabilitação, prescrita por profissional de saúde, com conhecimento dos materiais usados em sua confecção para correta especificação. Este estudo foi delimitado por uma pesquisa exploratória de órteses de membros superiores, do segmento mão e punho, onde o objetivo foi averiguar se há padronização na descrição dos materiais utilizados em sua confeç̧ão. Foram realizadas buscas no banco de patentes do Instituto Nacional de Propriedade Industrial, na Agência Nacional de Vigilância Sanitária, portarias e manuais do Ministério da Saúde e artigos científicos. Com os dados obtidos, foi elaborada uma análise sincrônica do produto selecionado. Os resultados sugerem que não há padronização na descrição e composição dos materiais destes produtos. Averiguou-se inovações em órteses que utilizam manufatura aditiva por meio de impressão 3D.

Palavras Chave: Órteses; Materiais; Tecnologia Assistiva.

\section{Abstract}

One of the causes of work absence is hand-held accidents, accounting for $18 \%$ of all accidents reported. The orthosis is a device of assistive technology, used for rehabilitation, prescribed by health professional, with knowledge of the materials used in its preparation for correct specification. This research was delimited by an exploratory study of hand and wrist upper limb orthoses, where the objective was to determine whether there is standardization in the description of the materials used in its manufacture. Searches were carried out at the National Institute of Industrial Property patent bank, at the National Sanitary Surveillance Agency, and at Ministry of Health and scientific articles. With the data obtained, a synchronic analysis of the selected product was elaborated. The results 
suggest that there is no standardization in the description and composition of the materials of these products. We investigated innovations in orthoses that use additive manufacture through $3 D$ printing.

Keywords: Orthoses; Materials; Assistive Technology. 


\section{Introdução}

Qualquer lesão nas mãos ou punho, reduz a capacidade funcional no trabalho, nas atividades diárias e funções básicas, como higiene pessoal, preparo de alimentos, trabalho que envolvam digitação, dentre outros. Segundo o Anuário Estatístico de Acidentes de Trabalho - AEAT de 2015 registra 725.664 acidentes de trabalho, sendo as mãos, uma das principais causas de afastamentos do trabalho, representando $18 \%$ de todos os acidentes registados. A distribuição destes acidentes pode ser vista na figura 1.

Figura 1 - Acidentes de trabalho.

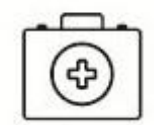

$100 \%$ DOS ACIDENTES DE TRABALHO

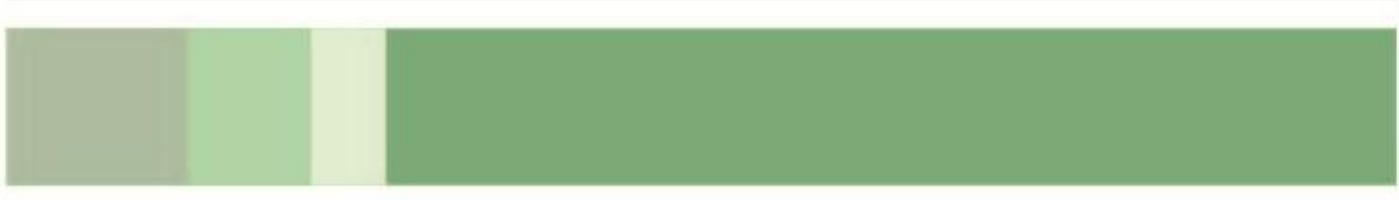

$18 \%$ FERIMENTOS MAO E PUNHO<smiles>C1#CCCCC1</smiles>

$8 \%$ Ferimentos măo e punho $6 \%$ Fratura măo e punho $4 \%$ Traumatismo superficial

Fonte: Os autores (2018)

Ferimentos do punho e da mão: 69.073 casos (representando $8 \%$ do total de casos); Fratura ao nível do punho e da mão: 49.992 casos (representando 6\% do total de casos); Traumatismo superficial do punho e da mão: 34.832 casos (representando $4 \%$ do total de casos). Em muitos destes casos, e prescrito o uso de órteses para um restabelecimento rápido da lesão. (BRASIL, 2015).

A Agência Nacional de Saúde Suplementar - ASN, define órteses como qualquer material permanente ou transitório que auxilie as funções de um membro, órgão ou tecido, cuja colocação ou remoção não requeiram a realização de ato cirúrgico. São utilizadas como recurso terapêutico, especificado pelo profissional de saúde, para alivio da dor e auxilio na reabilitação para um retorno rápido as atividades diárias (ANS, 2015).

Analisando o cenário aqui apresentado, destaca-se uma lacuna que norteou este estudo, que é: Em se tratando de órteses pré-fabricadas, disponíveis para venda em lojas, farmácias e ecommerce, há informações padronizadas acerca dos materiais, que auxiliam o profissional de saúde, na correta especificação para o usuário?

Desta forma, o objetivo deste estudo foi averiguar, por meio de uma pesquisa exploratória, se há padronização nas descrições dos materiais utilizados na confecção de órteses do segmento mão e punho, produzidos e disponibilizados no mercado. 
O conceito de pesquisa exploratória é: realizar um estudo preliminar sobre um assunto pouco conhecido pelo pesquisador. É uma pesquisa para aprender mais sobre os termos que a envolve e assim, conseguir formular hipóteses ou descobrir lacunas que irão nortear ou embasar futuros estudos (POUPART et al, 2008), (GIL, 2008)

Este estudo foi desenvolvido em quatro fases: 1. Revisão da literatura (Banco de patentes, leis/normas e artigos), 2. Pesquisa exploratória na Anvisa e site dos fornecedores selecionados, 3. Análise sincrônica do produto selecionado, 4. Verificação da padronização das informações, acerca dos materiais utilizados na confeç̧ão do produto selecionado.

\section{Fundamentos Teóricos}

O Manual de boas práticas do Ministérios da Saúde, elaborado pelo Grupo de Trabalho Interministerial sobre Órteses, Próteses e Materiais Especiais-GTI-OPME, padroniza a aquisição de órteses e próteses para todos os estabelecimentos de saúde ligados ao Sistema Único de Saúde SUS e saúde suplementar. O Manual também cita que "A órtese deve ser o mais simples possível sem perder seu propósito, sendo cosmeticamente e psicologicamente aceitável" (BRASIL, 2016).

Segundo Carvalho (2013), órteses para membros superiores são classificadas de acordo com as características mecânicas: estáticas ou dinâmicas. Órteses estáticas são as que evitam o movimento, que imobilizam as articulações em uma posição específica para alinhar as articulações, protegendo a região para o restabelecimento das funções.

Cardoso, Barbosa e Silva (2014), afirmam que órteses dinâmicas, também chamadas funcionais ou cinéticas, são prescritas, quando é necessária uma mobilidade controlada das articulações, com tração, que atua dirigindo o movimento, evitando movimentos indesejados, restringindo determinados movimentos, substituindo a força muscular ausente ou fraca, prevenindo ou corrigindo traumas e mantendo o equilíbrio muscular.

Cabe destacar que, o profissional de saúde com habilitação específica, deve fazer a prescrição e requerimento de órtese para o paciente, definindo qual fornecedor, determinando o tipo, o material e dimensões adequadas ao usuário. Os médicos que atendem por planos de saúde, seguem a resolução normativa da no 387 de 2015 e precisam justificar clinicamente sua prescrição, apresentando um requerimento, com indicação de três marcas de diferentes fabricantes. No entanto, a ASN não estabelece critérios de similaridade entre produtos, esta função é de responsabilidade da ANVISA. (BRASIL, 2015).

Em 08 de janeiro de 2015, foi criado o Grupo de Trabalho Interinstitucional - Órteses, Próteses e Materiais Especiais - GTI-OPME, por meio de portaria Interministerial no 38, composta pelos Ministérios da Saúde, Justiça e Fazenda. O grupo teve como um dos objetivos, formar subgrupos, para verificar a regulamentação vigente e unificar as informações em todo território nacional dividindo-se em três subgrupos: Subgrupo de Padronização de nomenclatura; Subgrupo de Protocolos e normas de uso e Subgrupo de Regulação econômica do setor. Cabe salientar que, mesmo citando critérios e normas para órteses, este grupo de trabalho, priorizou o levantamento das inconformidades nos procedimentos que envolvem os chamados Dispositivos Médicos Implantáveis - DMI, que precisam de controle rigoroso na sua aquisição e utilização e são regulados pela ANVISA (BRASIL, 2015).

O Grupo, citado acima, incluiu em suas recomendações, critérios para aquisição nas compras de produtos médicos, feito pelas unidades de saúde ligadas ao governo e que devem seguir as 
orientações elencadas na Instrução Normativa $n^{\circ} 1$ de 19 de janeiro de 2010 da Secretaria de Logística e Tecnologia da Informação do Ministério do Planejamento, Orçamento e Gestão. Esta instrução normativa define os requisitos ambientais para a obtenção de certificação do Instituto Nacional de Metrologia Normalização e Qualidade Industrial -INMETRO. Estes requisitos priorizam a compra de produtos sustentáveis ou de menor impacto ambiental em relação aos seus similares e estabelece que, os mesmos, sejam constituídos, no todo ou em parte, por material reciclado, atóxico, biodegradável, conforme ABNT NBR 15448-1 e 15448-2 dentre outras considerações (BRASIL, 2010).

Mesmo não sendo o objetivo deste estudo, é necessário fazer uma breve descrição de confecção de órteses customizadas, que é um segmento de mercado atuante para órteses de mão e punho. Estes produtos são feitos de forma artesanal, sendo atualmente um processo muito utilizado. Para a confecção destas órteses, são utilizados materiais termo moldáveis de baixa e alta temperatura além do gesso, gesso sintético, neoprene, lona, couro e diferentes tipos de metais na confecção das órteses de membros superiores sob medida. Para a confecção de órtese sob medida ou supervisão da moldagem, quando necessário, o princípio de apoiar, proteger, imobilizar e reestabelecer as funções do membro afetado, visam prevenir deformidades, que estão sujeitas a ocorrer, caso a órtese não seja moldada no usuário, respeitando os movimentos naturais e dos músculos evitando distrofias ou lesão nos tendões, garantindo as características anatômicas do punho e mão do paciente. (CARVALHO, 2013) (AGNELLI, TOYODA, 2003)

Outro tipo de órtese customizadas é a que utiliza a manufatura aditiva, neste caso, a impressão 3D, que está revolucionando a confecção de órteses, vindo de encontro ao anseio de profissionais e usuários pela facilitação do acesso, com uso de materiais inovadores, que utilizam matéria prima natural e sustentável, com valores reduzidos, possibilitando ao usuário final, acesso a um produto esteticamente inovador e com maior valor agregado nos aspectos de qualidade, inovação e preço, no entanto, este tipo de produto apresenta variáveis complexas e não tem ainda uma regulamentação especifica.

\section{Métodos da Pesquisa}

Este estudo é exploratório quanto aos objetivos e bibliográfica quanto aos meios, com amostragem não-probabilística intencional. Na amostra não-probabilística, os elementos da amostra são definidos por uma escolha deliberada de acordo com critérios e julgamento do pesquisador. É uma amostra por conveniência. A seleção dos dados ocorre em função dos elementos disponíveis para acesso (POUPART et al, 2008).

Para revisão da literatura, foram selecionadas as recentes portarias do Governo Federal do Brasil, do período de 2015 a 2017, relativas a órteses e três artigos científicos referentes a procedimentos, confecção e materiais utilizados em órteses. Foi realizada uma busca simples, de dados abertos, no site do Instituto Nacional de Propriedade Industrial - INPI, com o termo em português: órtese. Foram selecionados apenas os pedidos de registros de patentes de órteses de membros superiores que continha a palavra "mão" ou "punho", no título ou na descrição do pedido de patente. Foram encontrados 10 pedidos de patentes, conforme demonstrados no quadro 1 : 
Quadro 1 - Pedido de patentes de órteses mão ou punho no INPI

\begin{tabular}{|c|c|c|c|}
\hline No Patente INPI & Título & Materiais & Depositante \\
\hline $\begin{array}{l}\text { BR } 102013 \\
0197300 \text { A2 }\end{array}$ & $\begin{array}{l}\text { Órtese auto articulada para } \\
\text { correção do desvio ulnar } \\
\text { dos dedos e da articulação } \\
\text { metacarpo falangeana e } \\
\text { uso. }\end{array}$ & $\begin{array}{l}\text { Metal trefilado, ou laminado } \\
\text { ou aço inox, compósitos } \\
\text { poliméricos reforçados ou não } \\
\text { com fibra de carbono, } \\
\text { pulseiras elásticas, velcro ou } \\
\text { similares. }\end{array}$ & $\begin{array}{l}\text { Univ. de São Paulo - USP } \\
\text { (Br/Sp) }\end{array}$ \\
\hline $\begin{array}{l}\text { BR } 102014 \\
0232826 \text { A2 }\end{array}$ & $\begin{array}{l}\text { Luva instrumentada e } \\
\text { órtese ativa para a } \\
\text { quantificação e atenuação } \\
\text { do tremor humano. }\end{array}$ & $\begin{array}{l}\text { Material maleável e } \\
\text { confortável, que se ajusta } \\
\text { perfeitamente, na mão de uma } \\
\text { pessoa. }\end{array}$ & $\begin{array}{l}\text { Univ. Federal de } \\
\text { Uberlândia (Br/Mg) }\end{array}$ \\
\hline $\begin{array}{l}\text { BR } 112015 \\
0281800 \text { A2 }\end{array}$ & $\begin{array}{l}\text { Órtese proprioceptiva, } \\
\text { assegurando a } \\
\text { manutenção de uma } \\
\text { articulação }\end{array}$ & Tecido elástico, gel polímero & Millet Innovation (Fr) \\
\hline $\begin{array}{l}\text { BR } 112014 \\
0264899 \text { A2 } \\
\end{array}$ & Órtese de polegar & Não consta & Bsn Medical Gmbh (DE) \\
\hline PI 0803120-7 A2 & $\begin{array}{l}\text { Processo de confecção de } \\
\text { órtese em porcelana fria }\end{array}$ & $\begin{array}{l}\text { Películas de EVA, porcelana } \\
\text { fria, placa de zinco, tecido } \\
\text { antialérgico, cola brascoplast } \\
\text { standart, massa de modelar. }\end{array}$ & $\begin{array}{l}\text { Marilda Conceição Ferraz } \\
\text { Santana (BR/CE) / Ana } \\
\text { Paula Morais Braga } \\
\text { (BR/CE) / Karinne } \\
\text { Menezes Borges (BR/CE) }\end{array}$ \\
\hline PI 0600561-6 A2 & Órtese para mão & $\begin{array}{l}\text { Neoprene, tiras de borracha } \\
\text { vulcanizada, velcro e } \\
\text { termoplástico. }\end{array}$ & $\begin{array}{l}\text { Patrícia Neto Barroso } \\
\text { (BR/MG) }\end{array}$ \\
\hline PI 0504704-8 A8 & $\begin{array}{l}\text { Órtese funcional para mão } \\
\text { acionada por dispositivo } \\
\text { elétrico }\end{array}$ & $\begin{array}{l}\text { Malha ou material flexível, } \\
\text { tenodese }\end{array}$ & $\begin{array}{l}\text { Univ. Federal de Minas } \\
\text { Gerais }(\mathrm{Br} / \mathrm{Mg})\end{array}$ \\
\hline PI 0406109-8 A2 & $\begin{array}{l}\text { Órtese a base de } \\
\text { compósito polímero e fibra } \\
\text { de vidro e seu processo de } \\
\text { fabricação }\end{array}$ & $\begin{array}{l}\text { Molde de gesso, desmoldante } \\
\text { PVA1, resina com peróxido de } \\
\text { hidrogênio, fibra de vidro, } \\
\text { anilina, velcro. }\end{array}$ & $\begin{array}{l}\text { Fundação Edson Queiroz } \\
\text { (BR/CE) }\end{array}$ \\
\hline $\begin{array}{l}\text { MU } 8100835-0 \\
\text { U2 }\end{array}$ & $\begin{array}{l}\text { Órtese de membro } \\
\text { superior }\end{array}$ & $\begin{array}{l}\text { Haste com ponta } \\
\text { emborrachada }\end{array}$ & $\begin{array}{l}\text { Lecian Cardoso Lopes } \\
\text { (BR/SC) }\end{array}$ \\
\hline PI 8701134-4 A2 & $\begin{array}{l}\text { Órtese para recuperação } \\
\text { dos movimentos da mão } \\
\text { de hemiplégicos }\end{array}$ & Não consta & $\begin{array}{l}\text { Sylvia Helena Navajas } \\
\text { Cotrim [BR] / Cristina } \\
\text { Claussen Lippi Alves [BR] }\end{array}$ \\
\hline
\end{tabular}

FONTE: Os autores (2018)

O quadro 1 na coluna, "materiais" mostram que duas patentes não descrevem o material utilizado para confecção das órteses. Não há um nome comercial das patentes, não sendo possível fazer uma busca ou cruzamento de dados, e assim, verificar se estas patentes estão sendo comercializadas.

No levantamento inicial dos produtos encontrados no mercado, foram encontrados uma variedade de termos, nomes, tamanhos e estilos para designar órtese de segmento mão e punho. Foi necessário criar um critério para seleção do produto para à análise sincrônica. Nesta etapa, o objetivo foi: verificar a similaridade dos produtos tanto no aspecto de forma como função; verificar quais as informações de especificação dos materiais utilizados constavam no produto; verificar se havia padronização destas informações nos produtos similares. Para seleção dos produtos para a 
análise sincrônica, foi elaborado um filtro para a amostra das órteses pré-fabricadas, disponíveis no mercado, conforme mostra a Figura 2:

Figura 2 - Filtro para seleção de produtos e fornecedores para análise sincrônica.

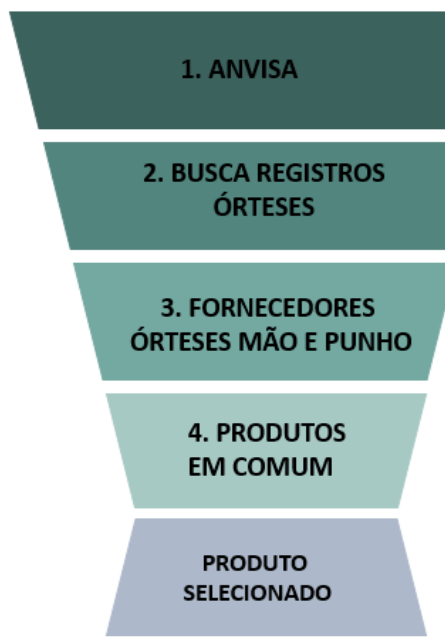

FONTE: Os Autores (2018)

Após definição do processo para seleção dos produtos para a análise sincrônica, o próximo passo foi a pesquisa no site da ANVISA, por meio do download de uma planilha em excell disponível no site, com dados atualizados sobre produtos de saúde com registros. Na planilha, foram criados filtros para pesquisa dos termos: órtese. Surgiram as palavras: órtese externa, órtese externa de fixação e órtese mínima de membros. Na coluna "detentor do registro de cadastro", foram verificados quais fornecedores/fabricantes constavam maior número de registro de produtos. Foi necessário criar um critério para seleção destes fornecedores (amostragem não probabilística intencional). Muitos fornecedores possuíam apenas um ou dois registros em sua maioria. Foram selecionados nove fornecedores com no mínimo dez registros como mostra o gráfico 1:

Gráfico 1 - Empresas x registros produtos Anvisa

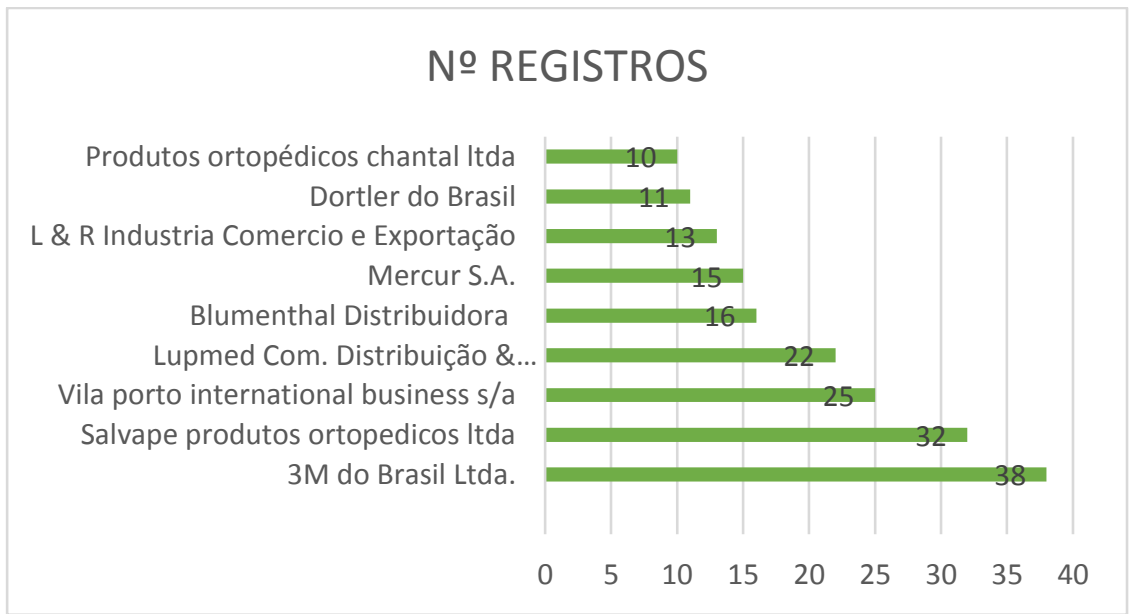

FONTE: Os Autores (2018) 
Após a seleção dos fornecedores, foram filtrados os quatro fornecedores com maior número de registros na Anvisa, nesta etapa, acima de 20 registros, sendo eles: $3 \mathrm{M}$ do Brasil (38 produtos), Salvapé produtos ortopédicos Ltda (32 produtos), Mercur S.A (25 produtos), Hidroligth - L\&R Industria Comercio (22 produtos). A partir destes dados, foi elaborada uma análise sincrônica com o produto selecionado: órtese para o segmento mão e punho, com tala, um produto em comum aos quatros fornecedores.

A Análise Sincrônica ou paramétrica, segundo Baxter (2000), serve para comparar os produtos existentes ou concorrentes em termos quantitativos, qualitativos e classificatórios. Os aspectos quantitativos são expressados numericamente como tamanho, peso, preço. Os qualitativos são subjetivos como: conforto, eficiência e beleza que são percebidos por meio dos materiais, textura e acabamentos, desta forma, pode-se também identificar inovações, analisando de forma crítica produtos similares. Por similar entende-se que são produtos que atendem as mesmas funções e que satisfaça as mesmas necessidades para o qual foram adquiridos. 0 quadro 2 traz a análise sincrônica dos quatro fornecedores selecionados segundo os critérios apresentados anteriormente.

Quadro 2 - Análise sincrônica órteses industrializadas

\begin{tabular}{|c|c|c|c|c|}
\hline Dados & Produto 1 & Produto 2 & Produto 3 & Produto 4 \\
\hline \multicolumn{5}{|l|}{ Órtese } \\
\hline Empresa & $3 \mathrm{M}$ & SALVAPE & MERCUR & L\&R - HIDROLIGTH \\
\hline Modelo & $3 \mathrm{M}$ futuro ${ }^{\mathrm{tm}}$ & REF. 436 & REF. BC0656-P & REF. OR57 \\
\hline $\begin{array}{l}\text { País de } \\
\text { origem }\end{array}$ & EUA & BRASIL & BRASIL & BRASIL \\
\hline Material & $\begin{array}{l}\text { Tecido transpirável, } \\
\text { materiais macios e } \\
\text { sem látex. }\end{array}$ & $\begin{array}{l}\text { Tecido de algodão, } \\
\text { proteção interna de } \\
\text { plástico, velcro }\end{array}$ & $\begin{array}{l}\text { 100\% Tecido de } \\
\text { algodão, velcro }\end{array}$ & $\begin{array}{l}\text { Borracha de } \\
\text { cloropreno } \\
\text { revestida com } \\
\text { tecido } 100 \% \\
\text { poliamida. }\end{array}$ \\
\hline Tamanho & $\mathrm{P} / \mathrm{M} / \mathrm{G} / \mathrm{GG}$ & $\mathrm{P} / \mathrm{M} / \mathrm{G} / \mathrm{GG} / \mathrm{XGG}$ & $P / M / G / G G$ & $\mathrm{P} / \mathrm{M} / \mathrm{G} / \mathrm{GG}$ \\
\hline preço & $\mathrm{R} \$ 99,00$ & $\mathrm{R} \$ 63,54$ & $\mathrm{R} \$ 39,00$ & $\mathrm{R} \$ 44,00$ \\
\hline $\begin{array}{l}\text { Característi- } \\
\text { cas }\end{array}$ & $\begin{array}{l}\text { Talas de alumínio, } \\
\text { tiras ajustáveis. }\end{array}$ & $\begin{array}{l}\text { Em tecido, fechos, } \\
\text { dedos livres, laváveis. }\end{array}$ & $\begin{array}{l}\text { Splint removível, } \\
\text { discreto, leve e } \\
\text { confortável }\end{array}$ & $\begin{array}{l}3 \text { tiras com tala } \\
\text { interna, orifício } \\
\text { para o polegar. }\end{array}$ \\
\hline Inovação & $\begin{array}{l}\text { Suporte de pulso } \\
\text { personalizado e } \\
\text { memória para } \\
\text { melhor ajuste. }\end{array}$ & $\begin{array}{l}\text { Bolsa externa na } \\
\text { frente para } \\
\text { armazenamento das } \\
\text { talas anatômicas de } \\
\text { plástico rígido. }\end{array}$ & & \\
\hline
\end{tabular}


Continuação

\begin{tabular}{|c|c|c|c|c|}
\hline Indicações & $\begin{array}{l}\text { Síndrome do túnel do } \\
\text { carpo, pós-gipsita, } \\
\text { entorses e tendinites. }\end{array}$ & $\begin{array}{l}\text { Tendinite do punho, } \\
\text { artrite, lesões } \\
\text { ligamentares, } \\
\text { correção de posições } \\
\text { viciosas na artrite } \\
\text { reumatoide e outras } \\
\text { afecções de origem } \\
\text { traumática e } \\
\text { neurológica. }\end{array}$ & $\begin{array}{l}\text { Alívio da dor e } \\
\text { inflamação, distúrbios } \\
\text { traumáticos ou } \\
\text { neurológicos, pós- } \\
\text { operatórios ou pós- } \\
\text { gipsita. correção de } \\
\text { posições viciosas. } \\
\text { Lesões ligamentares, } \\
\text { artrose, artrite } \\
\text { reumatoide. Ler / } \\
\text { Dort. Tendinite, } \\
\text { tenossinovites. } \\
\text { Síndrome do túnel } \\
\text { carpo. }\end{array}$ & $\begin{array}{l}\text { Tratamento de } \\
\text { entorses, lesões, } \\
\text { lesões } \\
\text { ligamentares, } \\
\text { artrose, artrite } \\
\text { reumatóide. Ler / } \\
\text { Dort. Tendinite, } \\
\text { tenossinovite. } \\
\text { Síndrome do túnel } \\
\text { carpo. Síndrome } \\
\text { de Quervain. }\end{array}$ \\
\hline
\end{tabular}

FONTE: Os Autores (2018)

As informações transcritas no quadro de análise sincrônica foram coletadas dos sites dos fabricantes e lojas online onde os produtos foram disponibilizados para vendas.

\section{Resultados e Discussões}

Os dados apresentados no quadro 2, demonstram que mesmo se tratando de modelos similares, a descrição dos materiais e indicações de uso não são padronizadas.

Informações apresentadas pelos fornecedores, tais como: "Tecido transpirável, materiais macios e sem látex" não fornece subsídios para identificação da composição, propriedade e desempenho destes materiais, não oferecendo parâmetros para comparar os produtos entre si, no que se refere a sua composição. Também não permitem a deteç̧ão de possíveis inadequações oriundas de sua utilização ou cuidados com o uso, mostrando a discrepância das informações disponibilizadas como demonstrada em síntese no quadro 3.

Quadro 3-Síntese descrição dos materiais

\begin{tabular}{ccc}
\hline Produto & Material & Características \\
\hline 1 & $\begin{array}{c}\text { Tecido transpirável, materiais } \\
\text { macios e sem látex. }\end{array}$ & $\begin{array}{c}\text { Talas de alumínio, tiras } \\
\text { ajustáveis }\end{array}$ \\
\hline 2 & $\begin{array}{c}\text { Tecido de algodão, proteção } \\
\text { interna de plástico, velcro }\end{array}$ & $\begin{array}{c}\text { Em tecido, fechos, dedos } \\
\text { livres, laváveis. }\end{array}$ \\
\hline 3 & 100\% Tecido de algodão, velcro & $\begin{array}{c}\text { Splint removível, discreto, } \\
\text { leve e confortável }\end{array}$ \\
& & Borracha de cloropreno revestida \\
com tecido 100\% poliamida.
\end{tabular}

FONTE: Os Autores (2018) 
O uso especifico de um material, no contexto de produção e utilização, está fundamentado em quatro pilares: processamento, estrutura, propriedades e desempenho do material. Um dos problemas no que se refere ao desenvolvimento de produtos, é a correta especificação do material mais adequado para um uso específico. (CALISTER, 2016).

Segundo Pereira et al (2017) a escolha do material para a confecção de um produto é essencial, para determinar a qualidade, o uso correto, o conforto, dentre outros fatores, tais como resistência mecânica e desempenho do material. Para o projeto de órteses de membros superiores (mão e punho), o autor cita alguns requisitos de materiais, solicitado por fisioterapeutas, tais como: a parte rígida deve ter resistência suficiente para não se quebrar com o uso; o tecido que reveste a órtese deve ser lavável, não causar alergias ou irritar a pele e permitir a transpiração; ter uma boa fixação no punho para não se mover com facilidade e manter a imobilização do punho.

O atendimento à essas solicitações, só são possíveis, com o conhecimento da composição, propriedade e desempenho destes materiais, para a correta especificação do produto em função do material mais adequado para um uso específico.

Por meio da análise sincrônica, foi observado que não há padronização nas descrições dos materiais utilizados para a confecção do produto. Em análise dedutiva, a não padronização pode gerar dificuldades de prescrição do produto para sua maior efetividade, confirmando as queixas do grupo GTI-OPME: Falta de informações padronizadas pelos órgãos reguladores e a dificuldade de acesso as informações que em alguns casos são conflitantes. A falta de clareza, tem gerado inúmeros transtornos para a população, pesquisadores e profissionais de saúde que precisam especificar os produtos deste segmento específico, sendo este último, um dos maiores problemas encontrado, como citado anteriormente.

A classificação de órteses, pela ANVISA é ambígua, sendo esta, uma das reivindicações do grupo GTI-OPME: A revisão do conceito OPME, deixando claro as diferenças entre órteses, próteses e materiais especiais pois os OPME contemplam uma categoria amplas de produtos e não há uma definição clara do termo para estes produtos industrializados (BRASIL, 2016)

As queixas se estendem a falta de informações padronizadas pelos órgãos reguladores e a dificuldade de acesso as informações que em alguns casos são conflitantes. Como exemplo, foi encontrado no site da ANVISA, disponibilizado pela ouvidoria, o relatório estatístico bimestral, do período de maio e junho, onde foram registradas 318 (Trezentas e dezoito) reclamações dos usuários sobre a dificuldade de acesso ao site/sistema e 118 (cento e dezoito) queixas relativas a normas e publicações questionáveis (BRASILIA,2017).

Esta falta de clareza tem gerado inúmeros transtornos para a população, pesquisadores e profissionais de saúde que precisam especificar os produtos deste segmento específico, dificultando a pesquisa de termos em sites de busca e nas plataformas da Anvisa.

No site do INPI , foram encontradas as mesmas dificuldades. Há problemas com as informações na busca de patentes como a não descrições dos materiais ou informações insuficientes tornando difícil o acesso a busca de dados (INPI, 2017).

Em relação aos números de acidentes de trabalho, os dados levantados registram 153.897 acidentes com as mãos. Estes são dados registrados, podendo ser bem maiores, levando-se em conta que muitos trabalhadores não têm carteira assinada e, portanto, não tem a obrigatoriedade de registro do acidente ocorridos no local do trabalho. (BRASIL, 2015) 
Em relação ao quadro de registro de patentes (Quadro 1), não foi possível relacionar os dados encontrados com nenhum produto comercializado no segmento de órteses comercializadas. Não foram encontrados indicadores da relação do número de patentes com o número de produtos comercializáveis.

Mesmo não sendo o objeto deste estudo, é pertinente citar uma informação relevante que surgiu no decorrer da pesquisa exploratória: Há inovações de materiais usados na confecção de órteses pré-fabricadas e customizadas, que não entraram na análise sincrônica, por não estarem dentro do escopo e critérios estabelecidos para a pesquisa exploratória deste estudo.

Inovações, segundo o Manual de Oslo (2004), são a implementação de um novo, ou significativamente melhorado, produto (bem ou serviço), processo, um novo método de marketing, ou novo método organizacional em práticas de negócio, organização do ambiente de trabalho, ou relações externas. Este Manual é a principal fonte internacional de diretrizes para coleta e uso de dados sobre atividades inovadoras da indústria redigida pela Organização para a Cooperação e o Desenvolvimento Econômico - OCDE da Comunidade Europeia, usado como referência para a padronização de conceitos, metodologias e construção de estatísticas e indicadores de pesquisa e desenvolvimento.

Uma startup, conhecida como Fix-It, está produzindo órteses por meio de manufatura aditiva (impressão 3D), feitas em PLA, um polímero biodegradável à base de fontes renováveis como milho e cana de açúcar.

Os Imobilizadores termos moldáveis, ou PunhoFix (figura 4), como são chamadas essas órteses para segmento mão e punho, são termo-moldáveis, adaptando-se, segundo a empresa, à anatomia do paciente, permitindo maior ventilação, sem acumulo de sujeira, evitando o mau-cheiro sendo resistentes à água (podem ser usadas durante o banho), além de possuírem design inovador e cores diferenciadas. (FIX-IT, 2017).

Figura 4 - Órtese Punhofix
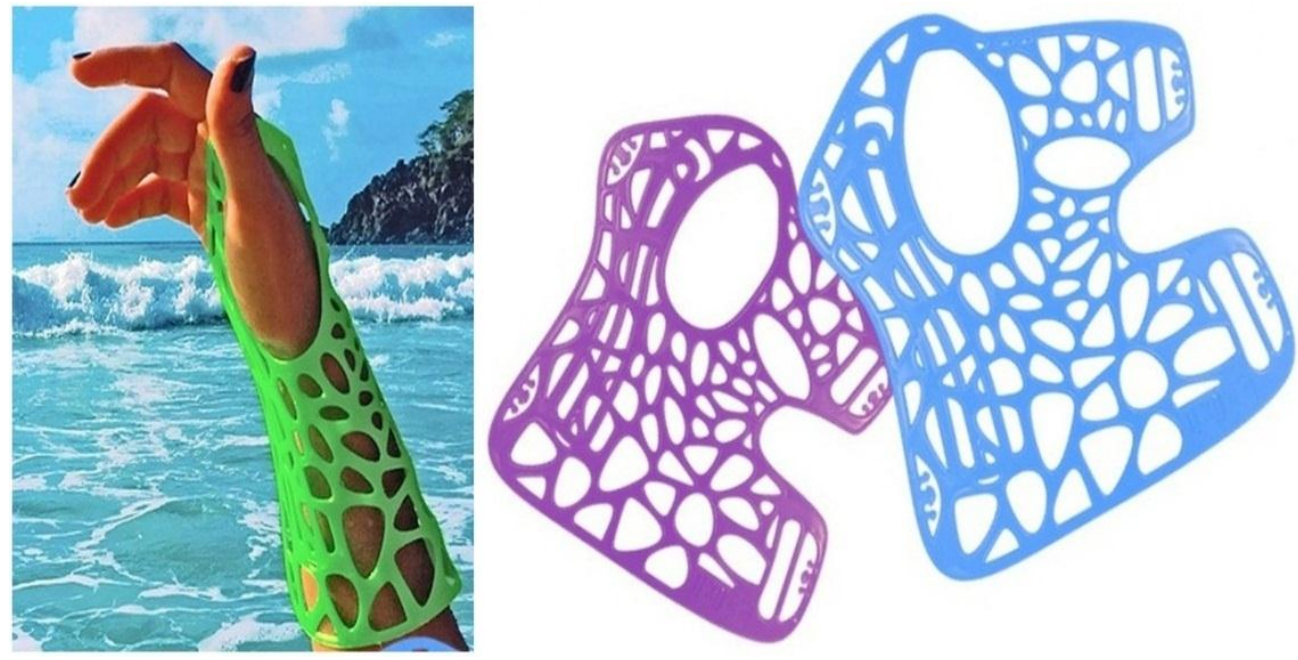

Fonte: www.usefix.it/ (2018)

A empresa indica este produto para casos de lesões de mãos e punhos, para tratamentos que exijam imobilização, para alívio da dor e inflamação, correção de posturas viciosas do punho, 
afecções de origem traumática ou neurológica, pós-operatório ou após a retirada do gesso, instabilidade de punho, lesões por esforço repetitivo tais como tendinites, síndrome túnel do carpo, tenossinovites ou ainda para repouso e proteção articular em condições inflamatórias agudas, como artrite reumatoide, artrose ou prevenção de lesões recidivas no retorno às atividades para recuperação rápida, cômoda e eficiente, aliviando a dor. (FIX-IT, 2017).

Os produtos são revendidos em e-commerce nos mesmos moldes dos produtos descritos na análise sincrônica.

\section{Considerações Finais}

Verificou-se nesta pesquisa exploratória, que, a maioria dos estudos disponíveis tratam de métodos, processos, aplicações e adequações aos usuários, no entanto, poucos tratam da padronização e normatização das informações disponíveis para usuários, profissionais e indústria. Visando contribuir com um debate sobre o tema apresentado, este estudo sugere algumas abordagens para futuros estudos:

1. Dimensionamento do quadro atual da indústria nacional de órteses;

2. Fichas técnicas padronizadas dos materiais utilizados, contendo os termos técnicos de sua composição, assim como ocorre com os cosméticos, que trazem em sua embalagem, sua composição química e que são regulados pela ANVISA.

3. Inserção do número da patente na descrição dos produtos, tornando possível, um cruzamento de informações entre produção de patentes e produtos disponibilizadas no mercado.

4. Criação e Padronização de códigos de todos os produtos "órteses" pela indústria brasileira, que poderiam ser utilizados por todos os atores deste mercado, unificando as informações sobre o produto incluindo os órgãos reguladores.

5. Criação de Apps para tornar mais dinâmica e intuitiva as buscas de informações nos sites do INPI e ANVISA com acesso fácil e rápido a qualquer cidadão, profissional de saúde, fornecedores, indústria, entre outros;

6. Regulamentação e Padronização das especificações dos materiais utilizados na confecção de próteses através da manufatura aditiva por meio da impressão 3D;

Visando contribuir com um debate sobre o tema apresentado, este estudo sugere o incentivo de pesquisas acadêmicas dos pontos citados anteriormente, que são relevantes, pois na academia há formação de opinião que promovem as mudanças que transformam a sociedade.

\section{Agradecimentos}

Agradecemos a Rede de Pesquisa e Desenvolvimento em Tecnologia Assistiva (RPDTA), ao Conselho Nacional de Desenvolvimento Científico e Tecnológico (CNPq), A Coordenação de Aperfeiçoamento de Pessoal de Nível Superior (CAPES). e a Universidade Federal do Paraná (UFPR). 


\section{Referências}

AGNELLI, Luciana B.; TOYODA, Cristina Y. Estudo de materiais para a confecção de órteses e sua utilização prática por terapeutas ocupacionais no Brasil. Cadernos de Terapia Ocupacional da UFSCar, vol. $11 n^{\circ} 2,2003$

AMADEU, M. S. U. S et al. Manual de normalização de documentos científicos de acordo com as normas da ABNT. Curitiba: Ed. UFPR, 2017. 329p Disponível em:

http://acervodigital.ufpr.br/bitstream/handle/1884/45654/Manual\%20de\%20Normalizacao\%20d e\%20Documentos\%20Cientificos.pdf?sequence=1\&isAllowed=y Acesso em 02 de out. 2017

ANS - Agência Nacional de Saúde Suplementar. Relatório final do Grupo de Trabalho Externo de Órteses, Próteses e Materiais Especiais. Rio de Janeiro: 2016. Disponível em:

http://www.ans.gov.br/images/stories/Particitacao_da_sociedade/2016_gt_opme/gt-opmerelatoriointegral.pdf Acesso em: 20 jul. 2017.

ANS. Resolução Normativa no 387, de 28 de outubro de 2015.

.http://www.ans.gov.br/component/legislacao/?view=legislacao\&task=TextoLei\&format=raw\&id= MzExMA== Acesso em: 20 jul. 2017.

ANVISA Agencia Nacional de Vigilância Sanitária. Disponível em :

http://portal.anvisa.gov.br/consulta-produtos-registrados Acesso em: 05jul.2017

ANVISA. Ouvidoria Agencia Nacional de Vigilância Sanitária. Relatório Estatístico Bimestral

Maio/Jun 2017. Brasília, 2017. Disponível em:

http://portal.anvisa.gov.br/documents/111522/3256092/Relat\%C3\%B3rio+Estat\%C3\%ADstico+M aio-Junho+2017/86b7b8a9-02fa-400e-8b1d-cb5e53a4c3a2. Acesso em: 20 jul. 2017.

BAXTER, M. R. Projeto de produto: guia prático para o design de novos produtos. Tradução Itiro lida. - 2. ed. rev. - São Paulo: Blueher, 2000.

BRASIL. Ministério da Fazenda. Anuário Estatístico de Acidentes do Trabalho : 2015 vol. 1 (2009) Brasília : MF, 2015. 991p Disponível em: http://www.previdencia.gov.br/wpcontent/uploads/2017/05/aeat15.pdf . Acesso em 10 de jul. 2017.

BRASIL. Ministério do Planejamento, orçamento e gestão. Instrução Normativa no 01, 19 de janeiro de 2010 Brasil. Disponível em: https://www.governoeletronico.gov.br/documentos-earquivos/INSTRUCAO\%20NORMATIVA\%20N.\%2001\%20de\%202010\%20-

\%20Compras\%20Sustentav.pdf Acesso em: 22 jul. 2017.

BRASIL. Portaria Interministerial no 38, 08 de janeiro de 2015. Disponível em: http://bvsms.saude.gov.br/bvs/saudelegis/gm/2015/prt0038_08_01_2015.html Acesso em: 22 jul. 2017.

BRASIL. Subsecretaria Nacional de Promoção dos Direitos da Pessoa com Deficiência. Comitê de Ajudas Técnicas. Tecnologia Assistiva . - Brasília: CORDE, 2009. 138 p.

BRASÍLIA. Ministério da Saúde. Secretaria de Atenção à Saúde. Departamento de Atenção Especializada e Temática. Manual de boas práticas de gestão das Órteses, Próteses e Materiais Especiais. 2016. Disponível em:

http://bvsms.saude.gov.br/bvs/publicacoes/manual_praticas_gestao_proteses_materiais_especia 
is.pdf Acesso em: 20 jul. 2017.

CALLISTER, W.D.J.; RETHWISCH, D.G. Ciência e Engenharia de Materiais. Uma Introdução. 9ạ Edição. São Paulo: Ed.LTC. 2016.

CARDOSO, C.M.C.; Barbosa, D.M.; Silva, P.N. Órteses: Conceitos, Tipos e Produção em: BRASIL. Ministério da Saúde. Secretaria de Gestão do Trabalho e da Educação na Saúde. Técnico em Órteses e Próteses: Livro-Texto. Brasília: Ministério da Saúde, 2014 Disponível em: http://bvsms.saude.gov.br/bvs/publicacoes/tecnico_orteses_proteses_livro_texto.pdf Acesso em: 15 jul. 2017.

CARVALHO, J. A. Órteses: um recurso terapêutico complementar. Barueri, SP: Manole, 2a Edição. $2013376 p$.

FINEP. Manual de Oslo. Proposta de Diretrizes para Coleta e Interpretação de Dados sobre Inovação Tecnológica. Brasília:, 2004 Disponível em: http://www.finep.gov.br/images/afinep/biblioteca/manual_de_oslo.pdf Acesso em 15 de jul. 2017

FIX-IT - Healhcare Innovation Disponível em: https://www.usefix.it/ Acesso em: 22 jul. 2017.

GIL, Antônio C. Como elaborar projetos de pesquisa. 5. ed. São Paulo: Atlas, 2008

INPI - Instituto Nacional de Propriedade Industrial Disponível em: http://www.inpi.gov.br/pedidosem-etapas/faca-busca Acesso em: 22 jul. 2017

PARIS. Manual: Guidelines for collecting and interpreting innovation data (3 ed.)., France: OECD, 2005. Disponível em http://www.oecd-ilibrary.org/science-and-technology/oslomanual_9789264013100-en Acesso em Acesso em: 22 jul. 2017.

PEREIRA Andressa R. S. et al. Órtese de punho: materiais e ficha técnica em Revista Engenharia em Ação UniToledo, Araçatuba, SP, v. 02, n. 02, p. 128-143, set./dez. 2017.

PETTEN, A. M. V. N., ÁVILA A. F., Silva e LIMA, c. g., 2014, Efeito do uso de órtese de punho na função manual, Cadernos de Terapia Ocupacional da UFSCar, 22(1), pp 79-87. Disponível em: http://doi.editoracubo.com.br/10.4322/cto.2014.009 Acesso em: 25 jul. 2017.

POUPART, J. et al. A pesquisa qualitativa: enfoques epistemológicos e metodológicos. Petrópolis: Editora Vozes; 2008.

RODRIGUES et al. Manufatura aditiva: estado da arte e framework de aplicações. GEPROS. Gestão da Produção, Operações e Sistemas, Bauru, Ano 12, no 3, jul-set/2017, p. 1-34 disponível em http://www.gepros.feb.unesp.br/index.php/gepros/article/view/1657 acesso em: 22 ago. 2017. 